February 10, 1997

\title{
Trust, Emotion, Sex, Politics, and Science: Surveying the Risk-Assessment Battlefield
}

\author{
Paul Slovic \\ Decision Research \\ 1201 Oak Street \\ Eugene, Oregon 97401
}

\begin{abstract}
Risk management has become increasingly politicized and contentious. Polarized views, controversy, and conflict have become pervasive. Research has begun to provide a new perspective on this problem by demonstrating the complexity of the concept "risk" and the inadequacies of the traditional view of risk assessment as a purely scientific enterprise.
\end{abstract}

This paper argues that danger is real,but risk is socially constructed. Risk assessment is inherently subjective and represents a blending of science and judgment with important psychological, social, cultural, and political factors. In addition, our social and democratic institutions, remarkable as they are in many respects, breed distrust in the risk arena.

Whoever controls the definition of risk controls the rational solution to the problem at hand. If risk is defined one way, then one option will rise to the top as the most cost-effective or the safest or the best. If it is defined another way, perhaps incorporating qualitative characteristics and other contextual factors, one will likely get a different ordering of action solutions. Defining risk is thus an exercise in power.

To appear in M. Bażerman, D. Messick, A. Tenbrunsel, and K. Wade-Benzoni (Eds.), Psychological Perspectives to Environment and Ethics in Management. San Francisco: Jossey-Bass.

Preparation of this paper was supported by the Alfred P. Sloan Foundation, the Electric Power Research Institute, and the National Science Foundation under Grants No. 91-10592 and SBR 94-122754. Portions of the text appeared in H. Kunreuther \& P. Slovic (1996). Science, values, and risk. The Annals of the American Academy of Political and Social Science, $54 \dot{5}, 116-125$. 
Trust, Emotion, Sex, Politics, and Science $\cdot 2$

Scientific literacy and public education are important, but they are not central to risk controversies. The public is not irrational. The public is influenced by emotion and affect in a way that is both simple and sophisticated. So are scientists. The public is influenced by worldviews, ideologies, and values; so are scientists, particularly when they are working at the limits of their expertise.

The limitations of risk science, the importance and difficulty of maintaining trust, and the complex, sociopolitical nature of risk point to the need for a new approach - one that focuses upon introducing more public participation into both risk assessment and risk decision making in order to make the decision process more democratic, improve the relevance and quality of technical analysis, and increase the legitimacy and public acceptance of the resulting decisions.

Recognizing interested and affected citizens as legitimate partners in the exercise of risk assessment is no short-term panacea for the problems of risk management. But serious attention to participation and process issues may, in the long run, lead to more satisfying and successful ways to manage risk.

\subsection{Introduction}

The practice of risk assessment has steadily increased in prominence during the past several decades, as risk managers in government and industry have sought to develop more effective ways to meet public demands for a safer and healthier environment. Dozens of scientific disciplines have been mobilized to provide technical information about risk, and billions of dollars have been expended to create this information and distill it in the context of risk assessments. 
Trust, Emotion, Sex, Politics, and Science $\cdot 3$

Ironically, as our society and other industrialized nations have expended this great effort to make life safer and healthier, many in the public have become more, rather than less, concerned about risk. These individuals see themselves as exposed to more serious risks than were faced by people in the past, and they believe that this situation is getting worse rather than better. Nuclear and chemical technologies (except for medicines) have been stigmatized by being perceived as entailing unnaturally great risks (Gregory, Flynn, \& Slovic, 1995). As a result, it has been difficult, if not impossible, to find host sites for disposing of high-level or low-level radioactive wastes, or for incinerators, landfills, and other chemical facilities.

Public perceptions of risk have been found to determine the priorities and legislative agendas of regulatory bodies such as the Environmental Protection Agency, much to the distress of agency technical experts who argue that other hazards deserve higher priority. The bulk of EPA's budget in recent years has gone to hazardous waste primarily because the public believes that the cleanup of Superfund sites is the most serious environmental threat that the country faces. Hazards such as indoor air pollution are considered more serious health risks by experts but are not perceived that way by the public (U.S. EPA, 1987).

Great disparities in monetary expenditures designed to prolong life, as shown in Table 1, may also be traced to public perceptions of risk. As noteworthy as the large sums of money devoted to protection from radiation and chemical toxins are the relatively small sums expended to reduce mundane hazards such as automobile accidents. Other studies have shown that serious risks from national disasters such as floods, hurricanes, and earthquakes generate relatively little public concern and demand for protection (Palm, 1995; Kunreuther, in press). 
Trust, Emotion, Sex, Politics, and Science $\bullet 4$

Table 1

Costs of a year of life saved by various interventions

- Flu shots $\$ 500$

- Water chlorination $\$ 4,000$

- Pneumonia vaccination $\$ 12,000$

- Breast cancer screening

$\$ 17,000$

- All medical interventions

$\$ 19,000$

- Construction safety rules

$\$ 38,000$

- All transportation interventions

$\$ 56,000$

- Highway improvement

$\$ 60,000$

- Home radon control

$\$ 141,000$

- Asbestos controls

$\$ 1.9$ million

- All toxin controls

$\$ 2.8$ million

- Arsenic emission controls

$\$ 6.0$ million

- Radiation controls

$\$ 10.0$ million

Source: Adapted from Tengs et al. (1995).

Such discrepancies are seen as irrational by many harsh critics of public perceptions. These critics draw a sharp dichotomy between the experts and the public. Experts are seen as purveying risk assessments, characterized as objective, analytic, wise, and rational — based upon the real risks. In contrast, the public is seen to rely upon perceptions of risk that are subjective, often hypothetical, emotional, foolish, and irrational (see, e.g., DuPont, 1980 or Covello, Flamm, Rodricks, \& Tardiff, 1983). Weiner (1993) defends the dichotomy, arguing that "This separation of reality and perception is pervasive in a technically sophisticated society, and serves to achieve a necessary emotional distance..." (p. 495).

In sum, polarized views, controversy, and overt conflict have become pervasive within risk assessment and risk management. A desperate search for salvation through risk-communication efforts began in the mid-1980s - yet, despite some localized successes, this effort has not stemmed the major conflicts or reduced much of the dissatisfaction with risk management. This 
Trust, Emotion, Sex, Politics, and Science $\cdot 5$

dissatisfaction can be traced, in part, to a failure to appreciate the complex and socially determined nature of the concept "risk." In the remainder of this paper, I shall describe several streams of research that demonstrate this complexity and point toward the need for new definitions of risk and new approaches to risk management.

\subsection{The Need for a New Perspective}

New perspectives and new approaches are needed to manage risks effectively in our society. Social science research has provided some valuable insights into the nature of the problem that, without indicating a clear solution, do point to some promising prescriptive actions.

For example, early studies of risk perception demonstrated that the public's concerns could not simply be blamed on ignorance or irrationality. Instead, research has shown that many of the public's reactions to risk (including reactions that may underlie the data in Table 1) can be attributed to a sensitivity to technical, social, and psychological qualities of hazards that are not well-modeled in technical risk assessments (e.g., qualities such as uncertainty in risk assessments, perceived inequity in the distribution of risks and benefits, and aversion to being exposed to risks that are involuntary, not under one's control, or dreaded). The important role of social values in risk perception and risk acceptance has thus become apparent (Slovic, 1987).

More recently, another important aspect of the risk-perception problem has come to be recognized. This is the role of trust. In recent years there have been numerous articles and surveys pointing out the importance of trust in risk management and documenting the extreme distrust we now have in many of the individuals, industries, and institutions responsible for risk management 
Trust, Emotion, Sex, Politics, and Science $\cdot 6$

(Slovic, 1993). This pervasive distrust has also been shown to be strongly linked to the perception that risks are unacceptably high and to political activism to reduce those risks.

A third insight pertains to the very nature of the concept "risk." Current approaches to risk assessment and risk management are based upon the traditional view of risk as some objective function of probability (uncertainty) and adverse consequences. I shall argue for a conception of risk that is starkly different from this traditional view. This new approach highlights the subjective and value-laden nature of risk and conceptualizes risk as a game in which the rules must be socially negotiated within the context of a specific problem.

\subsection{The Subjective and Value-Laden Nature of Risk Assessment}

Attempts to manage risk must confront the question: "What is risk?" The dominant conception views risk as "the chance of injury, damage, or loss" (Webster, 1983). The probabilities and consequences of adverse events are assumed to be produced by physical and natural processes in ways that can be objectively quantified by risk assessment. Much social science analysis rejects this notion, arguing instead that risk is inherently subjective (Funtowicz \& Ravetz, 1992; Krimsky \& Golding, 1992; Otway, 1992; Pidgeon, Hood, Jones, Turner, \& Gibson, 1992; Slovic, 1992; Wynne, 1992). In this view, risk does not exist "out there," independent of our minds and cultures, waiting to be measured. Instead, human beings have invented the concept risk to help them understand and cope with the dangers and uncertainties of life. Although these dangers are real, there is no such thing as "real risk" or "objective risk." The nuclear engineer's probabilistic risk estimate for a nuclear accident or the toxicologist's quantitative estimate of a chemical's carcinogenic risk are both based on theoretical models, whose structure is subjective and 
Trust, Emotion, Sex, Politics, and Science $\bullet$

assumption-laden, and whose inputs are dependent on judgment. As we shall see, nonscientists have their own models, assumptions, and subjective assessment techniques (intuitive risk assessments), which are sometimes very different from the scientists' models.

One way in which subjectivity permeates risk assessments is in the dependence of such assessments on judgments at every stage of the process, from the initial structuring of a risk problem to deciding which endpoints or consequences to include in the analysis, identifying and estimating exposures, choosing dose-response relationships, and so on.

For example, even the apparently simple task of choosing a risk measure for a well-defined endpoint such as human fatalities is surprisingly complex and judgmental. Table 2 shows a few of the many different ways that fatality risks can be measured. How should we decide which measure to use when planning a risk assessment, recognizing that the choice is likely to make a big difference in how the risk is perceived and evaluated?

An example taken from Wilson and Crouch (1983) demonstrates how the choice of one measure or another can make a technology look either more or less risky. For example, between 1950 and 1970, coal mines became much less risky in terms of deaths from accidents per ton of coal, but they became marginally riskier in terms of deaths from accidents per employee. Which measure one thinks more appropriate for decision making depends on one's point of view. From a national point of view, given that a certain amount of coal has to be obtained, deaths per million tons of coal is the more appropriate measure of risk, whereas from a labor leader's point of view, deaths per thousand persons employed may be more relevant. 


\section{Table 2}

Some ways of expressing mortality risks

- Deaths per million people in the population

- Deaths per million people within $\mathbf{x}$ miles of the source of exposure

- Deaths per unit of concentration

- Deaths per facility

- Deaths per ton of air toxic released

- Deaths per ton of air toxic absorbed by people

- Deaths per ton of chemical produced

- Deaths per million dollars of product produced

- Loss of life expectancy associated with exposure to the hazard

Each way of summarizing deaths embodies its own set of values (National Research Council, 1989). For example, "reduction in life expectancy" treats deaths of young people as more important than deaths of older people, who have less life expectancy to lose. Simply counting fatalities treats deaths of the old and young as equivalent; it also treats as equivalent deaths that come immediately after mishaps and deaths that follow painful and debilitating disease or long periods during which many who will not suffer disease live in daily fear of that outcome. Using "number of deaths" as the summary indicator of risk implies that it is as important to prevent deaths of people who engage in an activity by choice and deaths of those who have been benefiting from a risky activity or technology as to protect those who get no benefit from it. One can easily imagine a range of arguments to justify different kinds of unequal weightings for different kinds of deaths, but to arrive at any selection requires a value judgment concerning which deaths one considers most undesirable. To treat the deaths as equal also involves a value judgment. 


\subsection{Framing the Risk Information}

After a risk analysis has "negotiated," all the subjective steps of defining the problem and its options, selecting and measuring risks in terms of particular outcomes, determining the people at risk and their exposure parameters, and so on, one comes to the presentation of this information to the decision maker, often referred to as "framing." This process of presentation is also rife with subjectivity.

Numerous research studies have demonstrated that different (but logically equivalent) ways of presenting the same risk information can lead to different evaluations and decisions. One dramatic example of this comes from a study by McNeil, Pauker, Sox, and Tversky (1982), who asked people to imagine that they had lung cancer and had to choose between two therapies, surgery or radiation. The two therapies were described in some detail. Then one group of subjects was presented with the cumulative probabilities of surviving for varying lengths of time after the treatment. A second group of subjects received the same cumulative probabilities framed in terms of dying rather than surviving (e.g., instead of being told that $68 \%$ of those having surgery will have survived after one year, they were told that $32 \%$ will have died). Framing the statistics in terms of dying changed the percentage of subjects choosing radiation therapy over surgery from $18 \%$ to $44 \%$. The effect was as strong for physicians as for laypersons.

Equally striking changes in preference result from framing the information about consequences in terms of either lives saved or lives lost (Tversky \& Kahneman, 1981) or from describing an improvement in a river's water quality as a restoration of lost quality or an improvement from the current level (Gregory, Lichtenstein, \& MacGregor, 1993). 
Trust, Emotion, Sex, Politics, and Science $\cdot 10$

We now know that every form of presenting risk information is a frame that has a strong influence on the decision maker. Moreover, when we contemplate the equivalency of lives saved vs. lives lost, mortality rates vs. survival rates, restoring lost water quality vs. improving water quality, and so forth, we see that there are often no "right frames" or "wrong frames" — just "different frames."

\subsection{The Multidimensionality of Risk}

As noted above, research has also shown that the public has a broad conception of risk, qualitative and complex, that incorporates considerations such as uncertainty, dread, catastrophic potential, controllability, equity, risk to future generations, and so forth, into the risk equation. In contrast, experts' perceptions of risk are not closely related to these dimensions or the characteristics that underlie them. Instead, studies show that experts tend to see riskiness as synonymous with expected mortality, consistent with the dictionary definition given above and consistent with the ways that risks tend to be characterized in risk assessments (see, for example, Cohen, 1985). As a result of these different perspectives, many conflicts over "risk" may result from experts and laypeople having different definitions of the concept. In this light, it is not surprising that expert recitations of "risk statistics" often do little to change people's attitudes and perceptions.

There are legitimate, value-laden issues underlying the multiple dimensions of public risk perceptions, and these values need to be considered in risk-policy decisions. For example, is risk from cancer (a dread disease) worse than risk from auto accidents (not dreaded)? Is a risk imposed on a child more serious than a known risk accepted voluntarily by an adult? Are the deaths of 50 passengers in separate automobile accidents equivalent to the deaths of 50 passengers in one airplane crash? Is the risk from a polluted Superfund site worse if the site is located in a 
Trust, Emotion, Sex, Politics, and Science $\cdot 11$

neighborhood that has a number of other hazardous facilities nearby? The difficult questions multiply when outcomes other than human health and safety are considered.

\subsection{The Risk Game}

There are clearly multiple conceptions of risk (Shrader-Frechette, 1991). Dean and Thompson (1995) note that the traditional view of risk characterized by the event probabilities and consequences treats the many subjective and contextual factors described above as secondary or accidental dimensions of risk, just as coloration might be thought of as a secondary or accidental dimension of an eye. Accidental dimensions might be extremely influential in the formation of attitudes toward risk, just as having blue or brown coloration may be influential in forming attitudes toward eyes. Furthermore, it may be that all risks possess some accidental dimensions, just as all organs of sight are in some way colored. Nevertheless, accidental dimensions do not serve as criteria for determining whether someone is or is not at risk, just as coloration is irrelevant to whether something is or is not an eye.

I believe that the multidimensional, subjective, value-laden, frame-sensitive nature of risky decisions, as described above, supports a very different view, which Dean and Thompson call "the contextualist conception." This conception places probabilities and consequences on the list of relevant risk attributes along with voluntariness, equity, and other important contextual parameters. On the contextualist view, the concept of risk is more like the concept of a game than the concept of the eye. Games have time limits, rules of play, opponents, criteria for winning or losing, and so on, but none of these attributes is essential to the concept of a game, nor is any of them characteristic of all games. Similarly, a contextualist view of risk assumes that risks are characterized by some combination of attributes such as voluntariness, probability, intentionality, equity, and so on, but 
that no one of these attributes is essential. The bottom line is that, just as there is no universal set of rules for games, there is no universal set of characteristics for describing risk. The characterization must depend on which risk game is being played.

\subsection{Sex, Politics, and Emotion in Risk Judgments}

Given the complex and subjective nature of risk, it should not surprise us that many interesting and provocative things occur when people judge risks. Recent studies have shown that factors such as gender, race, political worldviews, affiliation, emotional affect, and trust are strongly correlated with risk judgments. Equally important is that these factors influence the judgments of experts as well as judgments of laypersons.

\section{$\underline{4.1} \underline{\operatorname{Sex}}$}

Sex is strongly related to risk judgments and attitudes. Several dozens of studies have documented the finding that men tend to judge risks as smaller and less problematic than do women (Brody, 1984; Carney, 1971; DeJoy, 1992; Gutteling \& Wiègman, 1993; Gwartney-Gibbs \& Lach, 1991; Pillisuk \& Acredolo, 1988; Sjöberg \& Drottz-Sjöberg, 1993; Slovic, Flynn, Mertz, \& Mullican, 1993; Slovic, Kraus, Lappe, Letzel, \& Malmfors, 1989; Spigner, Hawkins, \& Loren, 1993; Steger \& Witte, 1989; Stern, Dietz, \& Kalof, 1993).

A number of hypotheses have been put forward to explain sex differences in risk perception. One approach has been to focus on biological and social factors. For example, women have been characterized as more concerned about human health and safety because they give birth and are socialized to nurture and maintain life (Steger \& Witte, 1989). They have been characterized as physically more vulnerable to violence, such as rape, for example, and this may sensitize them to 
other risks (Baumer, 1978; Riger, Gordon, \& LeBailly, 1978). The combination of biology and social experience has been put forward as the source of a "different voice" that is distinct to women (Gilligan, 1982; Merchant, 1980).

A lack of knowledge and familiarity with science and technology has also been suggested as a basis for these differences, particularly with regard to nuclear and chemical hazards. Women are discouraged from studying science and there are relatively few women scientists and engineers (Alpen, 1993). However, Barke, Jenkins-Smith, and Slovic (1995) have found that female physical scientists judge risks from nuclear technologies to be higher than do male physical scientists.

Similar results with scientists were obtained by Malmfors, Mertz, Neil, Purchase, and Slovic (1996),

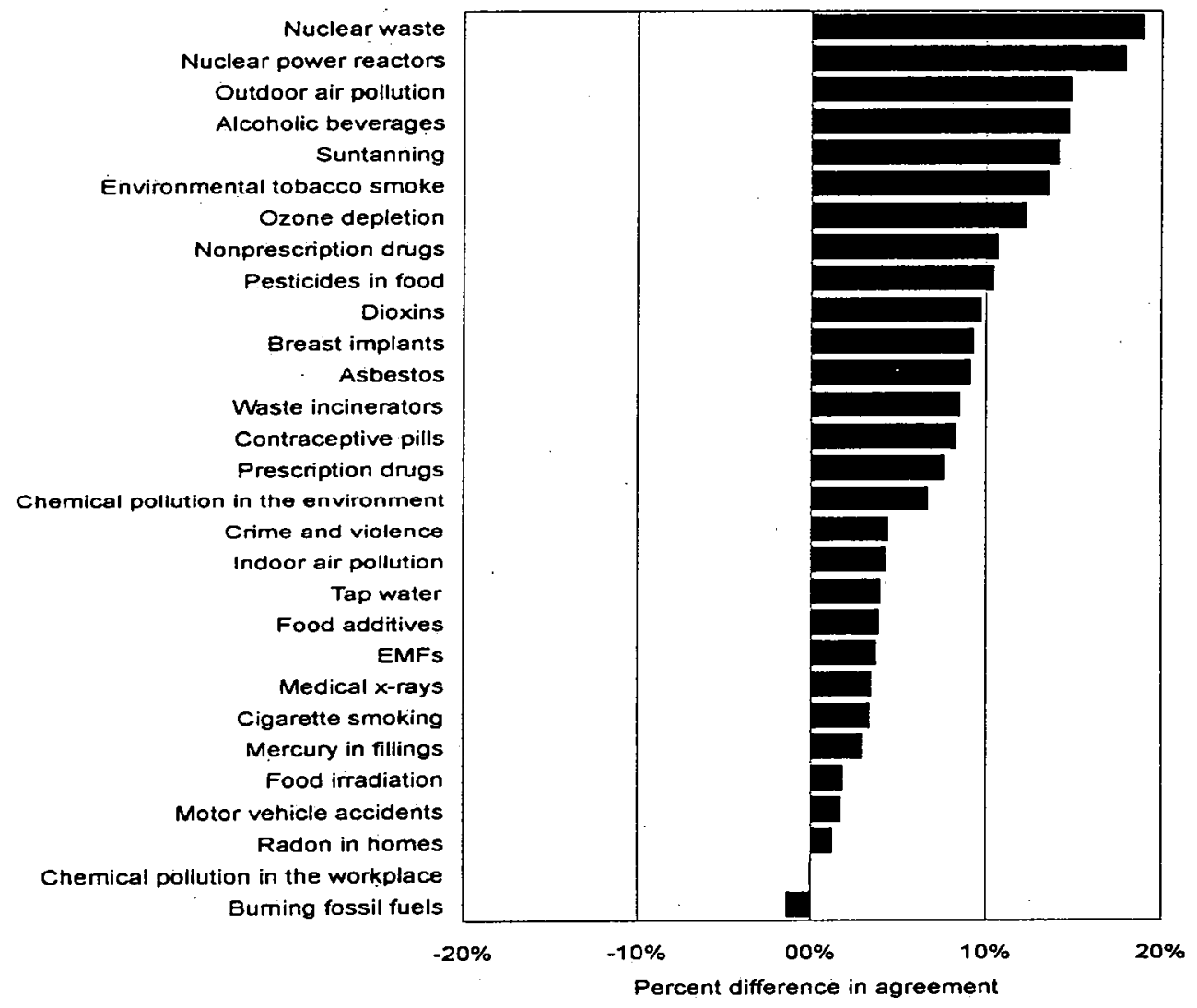

Figure 1. Perceived health risk to the average exposed British citizen as judged by members of the British Toxicological Society. Percent difference is percent female moderate and high risk responses minus percent male moderate and high risk responses ( $N=92$ females and 208 males). Source: Malmfors, Mertz, Neil, Purchase, and Slovic (1996). 
who found that female members of the British Toxicological Society were far more likely than male toxicologists to judge societal risks as high (see Figure 1). Certainly the female scientists in the studies by Barke et al. and Malmfors et al. cannot be accused of lacking knowledge and technological literacy. Something else must be going on.

Hints about the origin of these sex differences come from a study by Flynn, Slovic, and Mertz (1994) in which 1512 Americans were asked, for each of 25 hazard items, to indicate whether the hazard posed (1) little or no risk, (2) slight risk, (3) moderate risk, or (4) high risk to society. Figure 2 shows the difference in the percentage of males and females who rated a hazard as a "high risk." All differences are to the right of the $0 \%$ mark, indicating that the percentage of high-risk responses was greater for women on every item. A similar graph (Figure 3) shows that the percentage of high-risk responses was greater among people of color than among white respondents for every item sțudied.

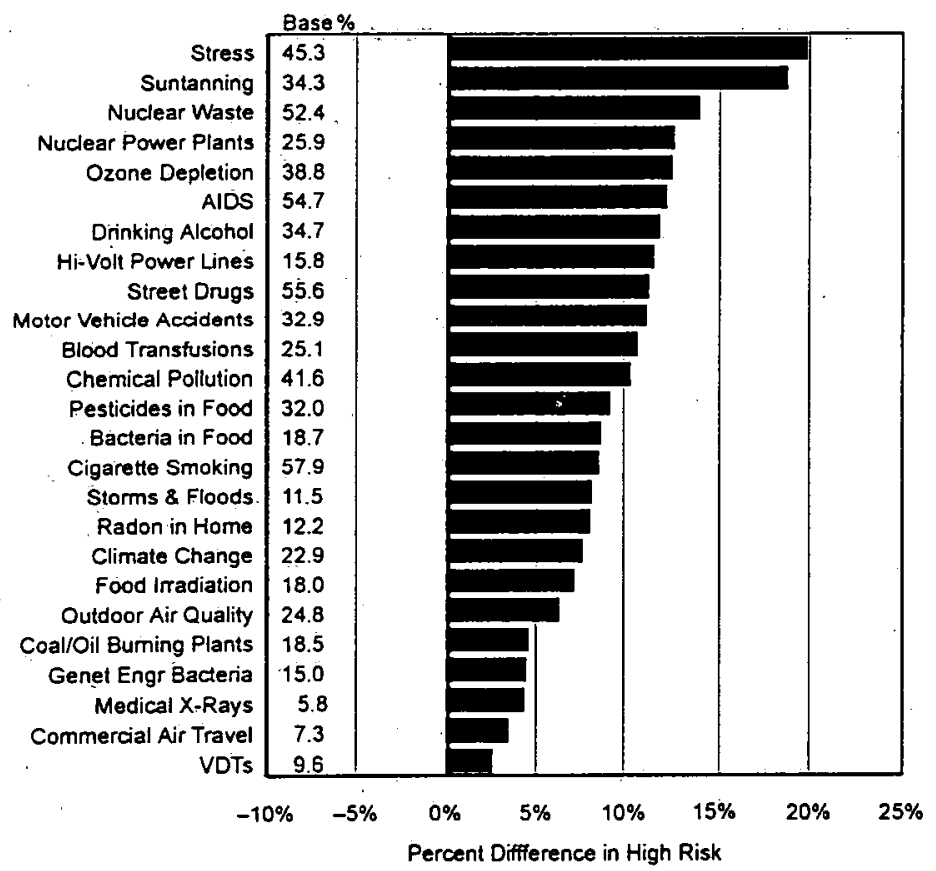

Figure 2. Perceived health risks to American public by gender: difference between males and females. Base percent equals male high-risk response. Percent difference is female high-risk response minus male high-risk response.

Source: Flynn, Slovic, and Mert (1994). 


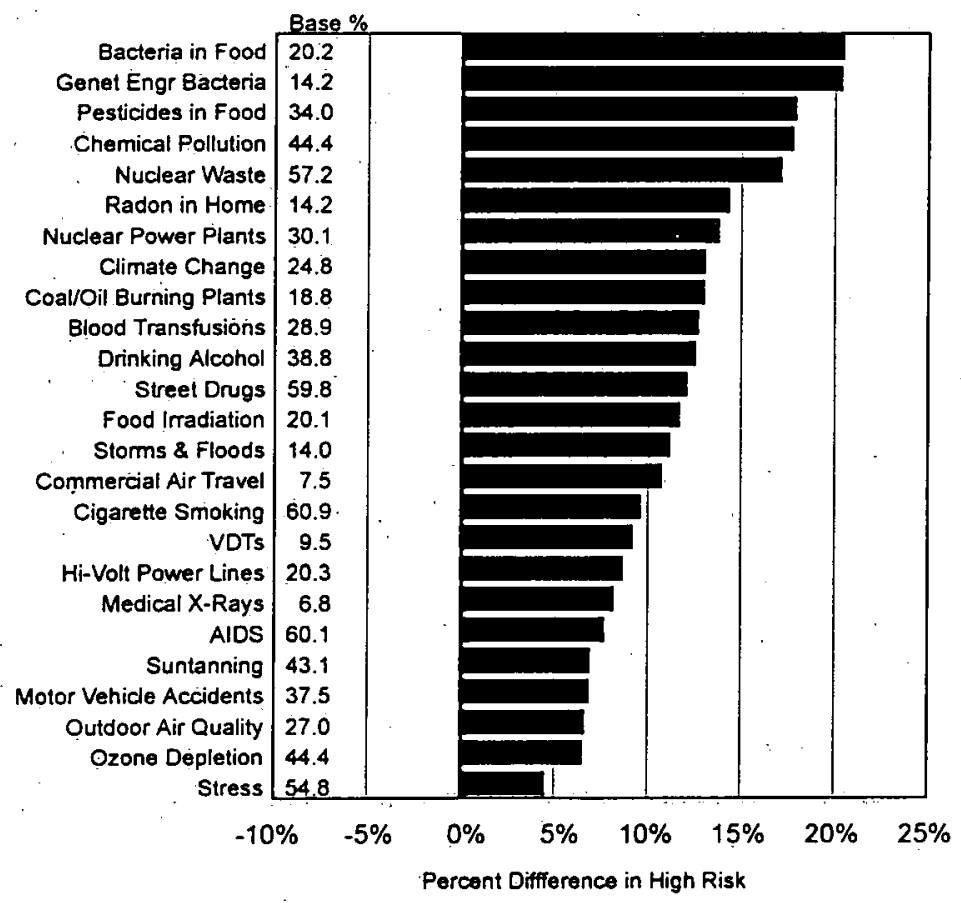

Figure 3. Perceived health risks to American public by race: difference between whites and nonwhites. Base percent equals white high-risk response. Percent difference is nonwhite high-risk response minus white high-risk response. Source: Flynn et al. (1994).

Perhaps the most striking result from this study is shown in Figure 4, which presents the mean risk ratings separately for white males, white females, nonwhite males, and nonwhite females. Across the 25 hazards, white males produced risk-perception ratings that were consistently much lower than the means of the other three groups. 


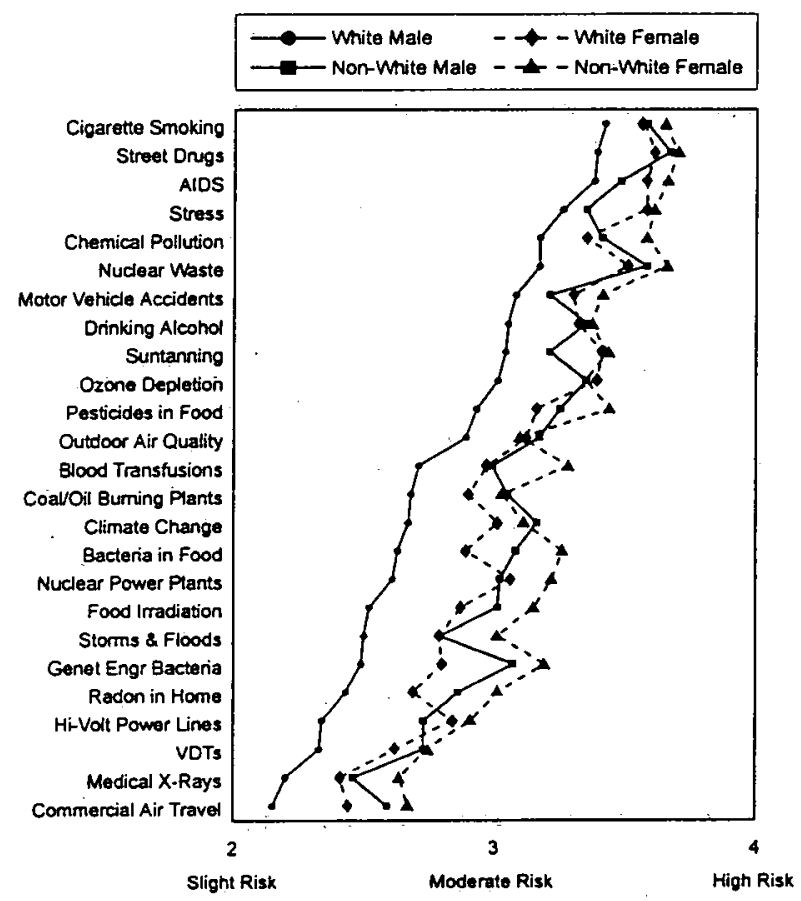

Figure 4. Mean risk-perception ratings by race and gender. Source: Flynn et al. (1994).

When the data underlying Figure 4 were examined more closely, Flynn et al. observed that not all white males perceived risks as low. The "white-male effect" appeared to be caused by about $30 \%$ of the white-male sample who judged risks to be extremely low. The remaining white males were not much different from the other subgroups with regard to perceived risk.

What differentiated these white males who were most responsible for the effect from the rest of the sample, including other white males who judged risks as relatively high? When compared to the remainder of the sample, the group of white males with the lowest risk-perception scores were better educated ( $42.7 \%$ college or postgraduate degree vs. $26.3 \%$ in the other group), had higher household incomes ( $32.1 \%$ above $\$ 50,000$ vs. $21.0 \%$ ), and were politically more conservative (48.0\% conservative vs. $33.2 \%$ ). Although perceived risk was inversely related to income and educational level, controlling for these differences statistically did not reduce much of the white- 
Trust, Emotion, Sex, Politics, and Science $\bullet 17$

male effect on risk perception. Figure 5 shows, for example, that white males exhibited far lower perceived risk at each of three levels of income and educational status.

Particularly noteworthy is the finding that the low risk-perception subgroup of white males

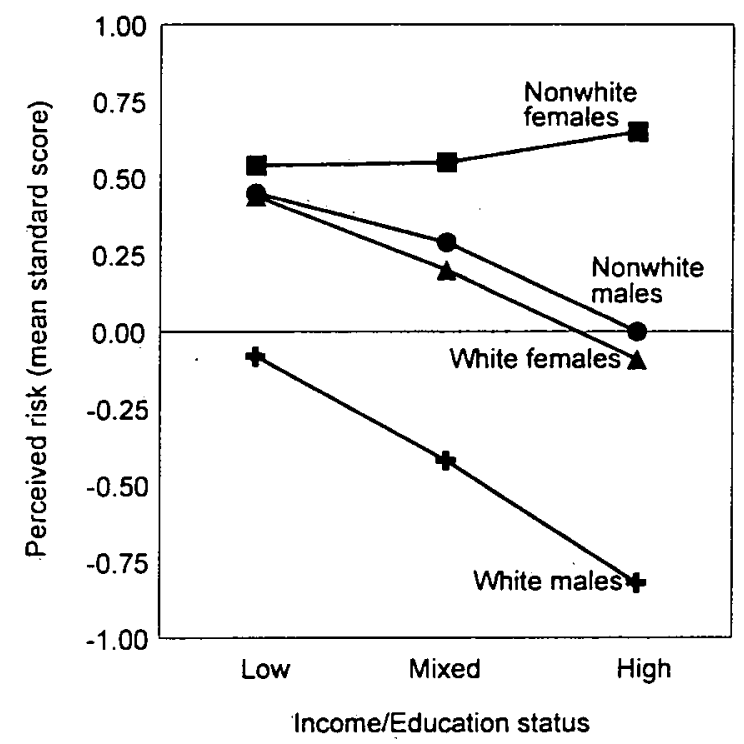

Note: High $=$ high income $(\$ 50 \mathrm{~K}+)$ and high education (college graduate + ): low $=$ low income $(<30 \mathrm{~K})$ and low education (high school or less); mixed $=$ all those not in high or low status groups .

Figure 5. Risk-perception index by race, gender, income and education. Source: National Survey conducted by Decision Research

also held very different attitudes than the other respondents. Specifically, they were more likely than the others to:

- Agree that future generations can take care of themselves when facing risks imposed upon them from today's technologies (64.2\% vs. $46.9 \%)$.

- Agree that if a risk is very small it is okay for society to impose that risk on individuals without their consent ( $31.7 \%$ vs. $20.8 \%)$.

- Agree that science can settle differences of opinion about the risks of nuclear power (61.8\% vs. $50.4 \%)$. 
Trust, Emotion, Sex, Politics, and Science $\cdot 18$

- Agree that government and industry can be trusted with making the proper decisions to manage the risks from technology ( $48.0 \%$ vs. $31.1 \%)$.

- Agree that we can trust the experts and engineers who build, operate, and regulate nuclear power plants $(62.6 \%$ vs. $39.7 \%)$.

- Agree that we have gone too far in pushing equal rights in this country (42.7\% vs. $30.9 \%)$.

- Agree with the use of capital punishment ( $88.2 \%$ vs. $70.5 \%)$.

- Disagree that technological development is destroying nature (56.9\% vs. $32.8 \%)$.

- Disagree that they have very little control over risks to their health ( $73.6 \%$ vs. $63.1 \%)$.

- Disagree that the world needs a more equal distribution of wealth ( $42.7 \%$ vs. $31.3 \%)$.

- Disagree that local residents should have the authority to close a nuclear power plant if they think it is not run properly ( $50.4 \%$ vs. $25.1 \%)$.

- Disagree that the public should vote to decide on issues such as nuclear power $(28.5 \%$ vs. $16.7 \%)$.

In sum, the subgroup of white males who perceive risks to be quite low can be characterized by trust in institutions and authorities and by anti-egalitarian attitudes, including a disinclination toward giving decision-making power to citizens in areas of risk management.

The results of this study raise new questions. What does it mean for the explanations of gender differences when we see that the sizable differences between white males and white females do not exist for nonwhite males and nonwhite females? Why do a substantial percentage of white males see the world as so much less risky than everyone else sees it?

Obviously, the salience of biology is reduced by these data on risk perception and race. Biological factors should apply to nonwhite men and women as well as to white people. The present data thus move us away from biology and toward sociopolitical explanations. Perhaps white males 
Trust, Emotion, Sex, Politics, and Science 19

see less risk in the world because they create, manage, control, and benefit from many of the major technologies and activities. Perhaps women and nonwhite men see the world as more dangerous because in many ways they are more vulnerable, because they benefit less from many of its technologies and institutions, and because they have less power and control over what happens in their communities and their lives. Although the survey conducted by Flynn, Slovic, and Mertz was not designed to test these alternative explanations, the race and gender differences in perceptions and attitudes point toward the role of power, status, alienation, trust, perceived government responsiveness, and other sociopolitical factors, in determining perception and acceptance of risk.

Inasmuch as these sociopolitical factors shape public perception of risks, we can see why traditional attempts to make people see the world as white males do, by showing them statistics and risk assessments, are unlikely to succeed. The problem of risk conflict and controversy goes beyond science. It is deeply rooted in the social and political fabric of our society.

\subsection{Risk Perception and Worldviews}

The influence of social, psychological, and political factors also can be seen in studies examining the impact of worldviews on risk judgments.

Worldviews are general social, cultural, and political attitudes that appear to have an influence over people's judgments about complex issues (Buss, Craik, \& Dake, 1986; Dake, 1991; Jasper, 1990). Dake (1991) has conceptualized worldviews as "orienting dispositions," because of their role in guiding people's responses. Some of the worldviews identified to date are listed below, along with representative attitude statements:

- Fatalism (e.g., "I feel I have very little control over risks to my health").

- Hierarchy (e.g., "Decisions about health risks should be left to the experts").

- Individualism (e.g., "In a fair system, people with more ability should earn more"). 
Trust, Emotion, Sex, Politics, and Science $\cdot 20$

- Egalitarianism (e.g., "If people were treated more equally, we would have fewer problems").

- Technological Enthusiasm (e.g., "A high-technology society is important for improving our health and social well-being").

People differ from one another in these views. Fatalists tend to think that what happens in life is preordained and one cannot change that. Hierarchists like a society organized such that commands flow down from authorities and obedience flows up the hierarchy. Egalitarians prefer a world in which power and wealth are more evenly distributed. Individualists like to do their own thing, unhindered by government or any other kind of constraints.

Dake (1991, 1992), Jenkins-Smith (1993) and others have measured worldviews with survey techniques and found them to be strongly linked to public perceptions of risk. My colleagues and I have obtained similar results. Peters and Slovic (in press), using the same national survey data analyzed for race and gender effects by Flynn et al. (1994), found particularly strong correlations between worldviews and attitudes toward nuclear power. Egalitarians tended to be strongly antinuclear; persons endorsing fatalist, hierarchist, and individualistic views tended to be pro-nuclear. Tables 3 and 4 illustrate these findings for one individualism item (Table 3) and one egalitarian item (Table 4). 


\section{Table 3}

Agreement or disagreement with an individualism worldview is associated with percentage of respondents who support building new nuclear power plants

\begin{tabular}{|c|c|}
\hline $\begin{array}{l}\text { Individualism worldview: In a fair } \\
\text { system people with more ability } \\
\text { should earn more }\end{array}$ & $\begin{array}{c}\text { Build new nuclear } \\
\text { power plants } \\
\text { (percent agree) }\end{array}$ \\
\hline Strongly disagree & $37.5 \%$ \\
\hline Disagree & 37.7 \\
\hline Agree & 47.2 \\
\hline Strongly agree & 53.4 \\
\hline
\end{tabular}

${ }^{a}$ The precise statement was: If your community was faced with a potential shortage of electricity, do you agree or disagree that a new nuclear power plant should be built to supply that electricity?

\section{Table 4}

Agreement or disagreement with an egalitarian worldiview is associated with percentage of respondents who support building new nuclear power plants

\begin{tabular}{|c|c|}
\hline $\begin{array}{l}\text { Egalitarian worldview: What this } \\
\text { world needs is a more equal } \\
\text { distribution of wealth }\end{array}$ & $\begin{array}{l}\text { Build new nuclear } \\
\text { power plants } \\
\text { (percent agree) }\end{array}$ \\
\hline Strongly disagree & $73.9 \%$ \\
\hline Disagree & 53.7 \\
\hline Agree & 43.8 \\
\hline Strongly agree & 33.8 \\
\hline
\end{tabular}

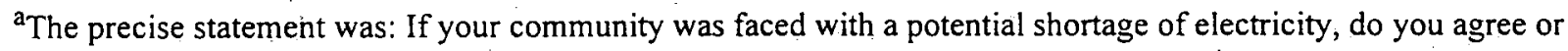
disagree that a new nuclear power plant should be built to supply that electricity?
} 
Trust, Emotion, Sex, Politics, and Science $\cdot 22$

When scales measuring the various worldviews were combined into a regression equation they exhibited considerable ability to predict perceptions of risk from nuclear power and attitudes toward accepting a new nuclear power plant in one's community (see Figure 6).

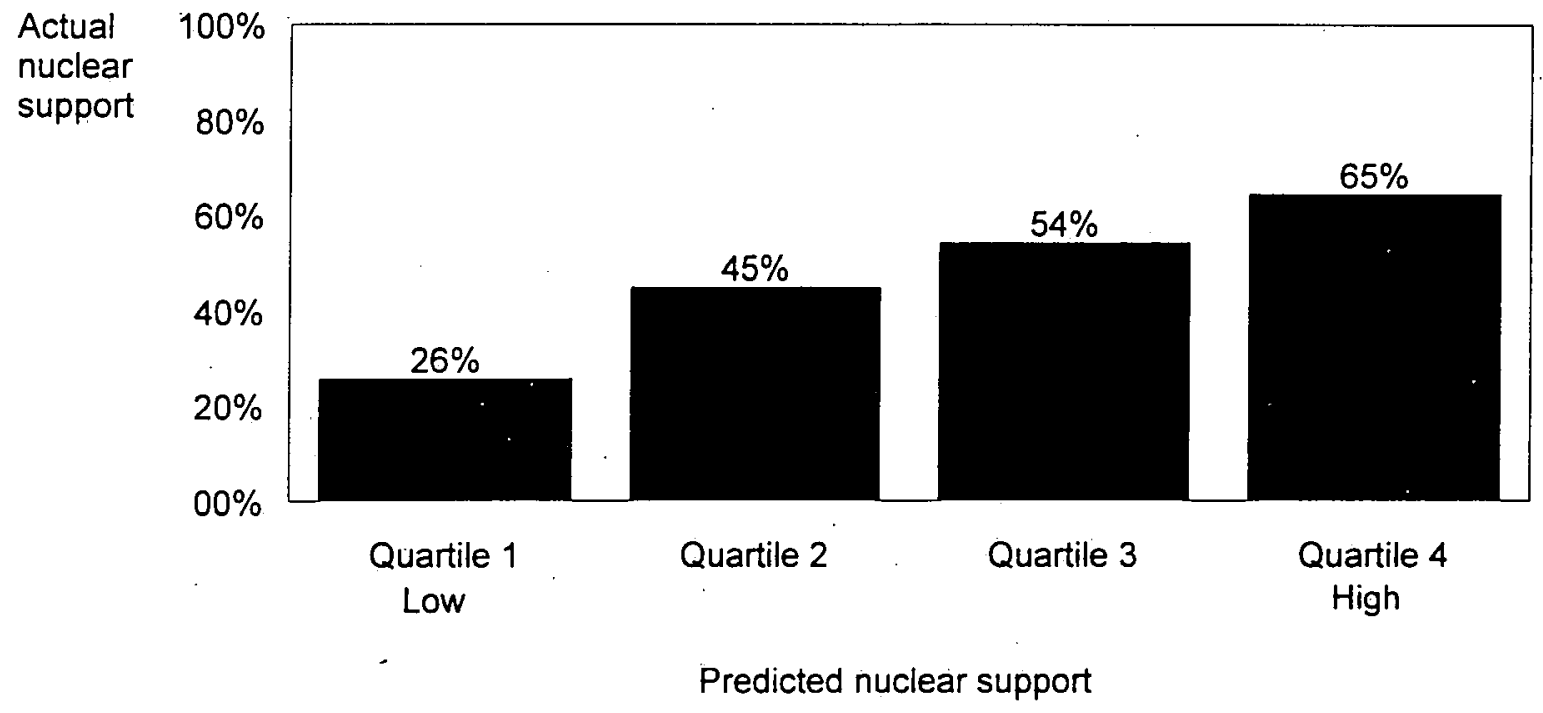

Figure 6. Relationship between predictions of nuclear support based on fatalism, hierarchism, individualism, and egalitarian worldviews and actual nuclear support. Actual nuclear support was based on the percent agreeing that, if their community was faced with a potential shortage of electricity, a new nuclear power plant should be built to supply that electricity.

\section{$\underline{4.3 \text { Risk Perception and Affect }}$}

The studies described in the preceding section illustrate the role of worldviews as orienting mechanisms. Research suggests that affect is also an orienting mechanism that directs fundamental psychological processes such as attention, memory, and information processing. Zajonc (1980), for example, argued that affective reactions to stimuli are often the very first reactions, occurring without extensive perceptual and cognitive encoding and subsequently guiding information processing and judgment. According to Zajonc, all perceptions may contain some affect. "We do not just see 'a house:' We see a handsome house, an ugly house, or a pretentious house" (p. 154). 
Trust, Emotion, Sex, Politics, and Science $\cdot 23$

He later adds, "We sometimes delude ourselves that we proceed in a rational manner and weigh all the pros and cons of the various alternatives. But this is probably seldom the actual case. Quite often 'I decided in favor of $X$ ' is no more than 'I liked $X$ ' ... We buy the cars we 'like,' choose the jobs and houses we find 'attractive,' and then justify these choices by various reasons ..." (p. 155).

If Zajonc is correct regarding the primacy and automaticity of affect, then affective reactions may also serve as orienting dispositions. Affect and worldviews may thus be functionally similar in that both may help us navigate quickly and efficiently through a complex, uncertain, and sometimes dangerous world. This view is schematized in Figure 7, which indicates that people's perceptions of risk and acceptance of risk and their trust in risk management are based on knowledge and experience. But the model in this figure also assumes that knowledge, experience, and ultimately our risk evaluations are themselves colored by two overarching phenomena - worldviews and affect.

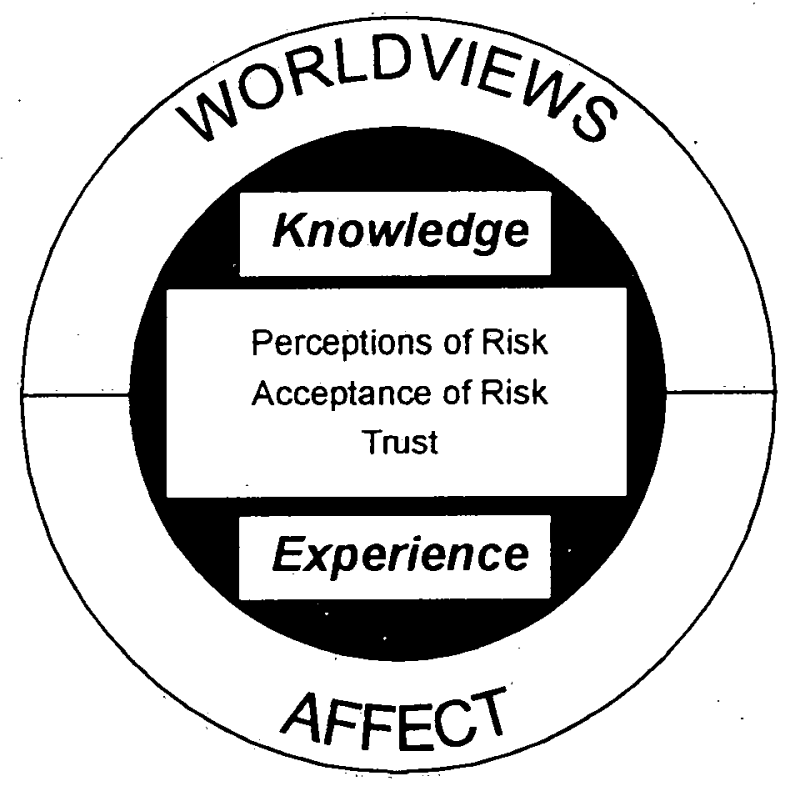

Figure 7. Schematic model of worldviews and affect as orienting dispositions. 
Trust, Emotion, Sex, Politics, and Science $\cdot 24$

One demonstration of the influence of affect on risk perception comes from a study by Johnson and Tversky (1983). They found that reading about a tragic death increased people's frequency estimates for many other causes of death. Johnson and Tversky interpreted this as an indication that the negative affect generated by the tragic story influenced all the subsequent estimates, regardless of the similarity between the tragic event and other fatal events.

Support for the conception of affect as an orienting mechanism also comes from a study by Alhakami and Slovic (1994). They observed that, whereas the risks and benefits to society from various activities and technologies (e.g., nuclear power, commercial aviation) tend to be positively associated in the world, they are inversely correlated in people's minds (higher perceived benefit is associated with lower perceived risk; lower perceived benefit is associated with higher perceived risk): This inverse relationship had been observed previously in numerous studies of risk perception (e.g., Fischhoff, Slovic, Lichtenstein, Read, \& Combs, 1978; Slovic, Kraus, Lappe, \& Major, 1991). Alhakami and Slovic found that this inverse relationship was linked to people's reliance on general affective evaluations when making risk/benefit judgments. When the affective evaluation was favorable (as with automobiles, for example), the activity or technology being judged was seen as having high benefit and low risk; when the evaluation was unfavorable (e.g., as with pesticides), risks tended to be seen as high and benefits as low. It thus appears that the affective response is primary, and the risk and benefit judgments are derived (at least partly) from it.

Slovic, Flynn, and Layman (1991) and Slovic, Layman, Kraus, Flynn, Chalmers, and Gesell (1991) studied the relationship between affect and perceived risk for hazards related to nuclear power. For example, Slovic, Layman, and Flynn asked respondents "What is the first thought or image that comes to mind when you hear the phrase 'nuclear waste repository?" After providing up 
Trust, Emotion, Sex, Politics, and Science $\cdot 25$

to three associations to the repository stimulus, each respondent rated the affective quality of these associations on a five-point scale, ranging from extremely negative to extremely positive.

Although most of the images that people evoke when asked to think about nuclear power or nuclear waste are affectively negative (e.g., death, destruction, war, catastrophe), some are positive (e.g., abundant electricity and the benefits it brings). The affective values of these positive and negative images appear to sum in a way that is predictive of our attitudes, perceptions, and behaviors. If the balance is positive, we respond favorably; if it is negative, we respond unfavorably. For example, the affective quality of a person's associations to a nuclear waste repository was found to be related to whether the person would vote for or against a referendum on a nuclear waste repository and to their judgments regarding the risk of a repository accident. Specifically, more than $90 \%$ of those people whose first image was judged very negative said that they would vote against a repository in Nevada; fewer than $50 \%$ of those people whose first image was positive said they would vote against the repository (Slovic, Flynn et al., 1991).

Using data from the national survey of 1500 Americans described earlier, Peters and Slovic (in press) found that the affective ratings of associations to the stimulus "nuclear power" were highly predictive of responses to the question: "If your community was faced with a shortage of electricity, do you agree or disagree that a new nuclear power plant should be built to supply that electricity?" Among the $25 \%$ of respondents with the most positive associations to nuclear power, $69 \%$ agreed to building a new plant. Among the $25 \%$ of respondents with the most negative associations, only $13 \%$ agreed. A comparison of these percentages with those in the extreme quartiles of Figure $6(65 \%$ and $26 \%$, respectively) shows that affect was even more powerful as a predictor of nuclear power support than the combined worldviews. When affect plus the various 
Trust, Emotion, Sex, Politics, and Science $\cdot 26$

worldviews were combined into one prediction equation, the ability to predict support for nuclear power was even stronger (see Figure 8).

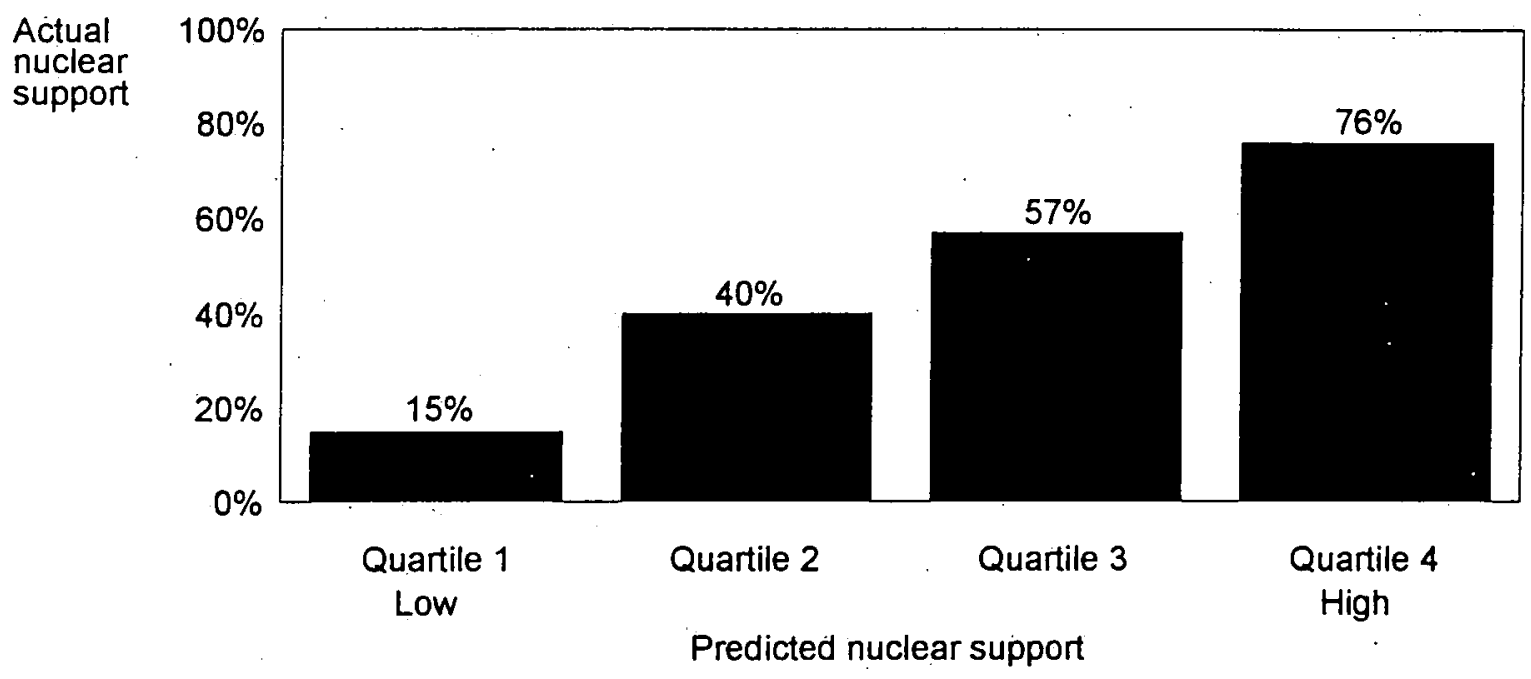

Figure 8. Relationship between predictions of nuclear support based on affect and worldviews and actual nuclear support. Actual nuclear support was based on the percent agreeing that, if their community was faced with a potential shortage of electricity, a new nuclear power plant should be built to supply that electricity. Source: Peters and Slovic (in press).

\subsection{Worldviews, Affect, and Toxicology}

Affect and worldviews seem to influence the risk-related judgments of scientists, as well as laypersons. Evidence for this comes from studies of "intuitive toxicology" that Torbjöm Malmfors, Nancy Neil, Iain Purchase, and I have been conducting in the U.S., Canada, and the UK during the past eight years. These studies have surveyed both toxicologists and laypersons about a wide range of concepts relating to risks from chemicals. We have examined judgments about the effects of chemical concentration, dose, and exposure on risk. We have also questioned our respondents about the value of animal studies for predicting the effects of chemicals on humans. Before showing how worldviews and affect enter into toxicologists' judgments, a brief description of some basic results will be presented. 
Trust, Emotion, Sex, Politics, and Science $\cdot 27$

Consider two survey items that we have studied repeatedly. One is statement $\mathrm{S}_{1}$ : "Would you agree or disagree that the way an animal reacts to a chemical is a reliable predictor of how a human would react to it?" The second statement, $\mathrm{S}_{2}$, is a little more specific: "If a scientific study produces evidence that a chemical causes cancer in animals, then we can be reasonably sure that the chemical will cause cancer in humans."

When members of the American and Canadian public responded to these items, they showed moderate agreement with $\mathrm{S}_{1}$; about half the people agreed and half disagreed that animal tests were reliable predictors of human reactions to chemicals. However, in response to $S_{2}$, which stated that the animal study found evidence of cancer, there was a jump in agreement to about $70 \%$ among both men and women respondents (see Figure 9). The important point about the pattern of response is that agreement was higher on the second item.

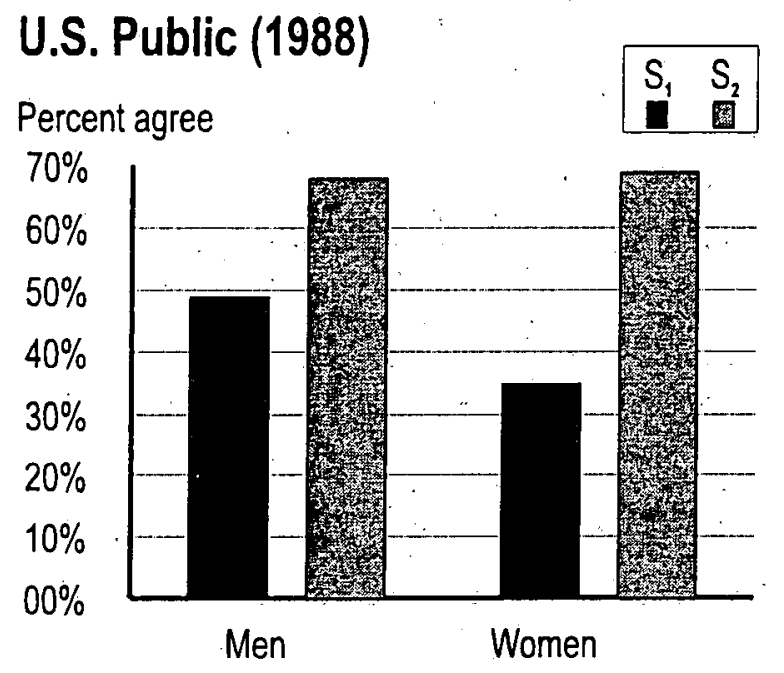

Figure 9. Agreement among members of the public in the United States for Statement $1\left(S_{1}\right)$ : "The way that an animal reacts to a chemical is a reliable predictor of how a human would react to it" and $\mathrm{S}_{2}$ : "If a scientific study produces evidence that a chemical causes cancer in animals, then we can be reasonably sure that the chemical will cause cancer in humans." Source: Kraus, Malmfors, and Slovic (1992).

What happens if toxicologists are asked about these two statements? Figure 10 shows that toxicologists in the U.S. and toxicologists in the UKK responded similarly to the public on the first statement but differently on the second. They exhibited the same rather middling level of agreement 
Trust, Emotion, Sex, Politics, and Science $\cdot 28$

with the general statement about animal studies as predictors of human health effects. ${ }^{1}$ However, when these studies were said to find evidence of carcinogenicity in animals, then the toxicologists were less likely to agree that the results could be extrapolated to humans. Thus, the same findings which lead toxicologists to be less willing to generalize to humans lead the public to see the chemical as more dangerous for humans. ${ }^{2}$

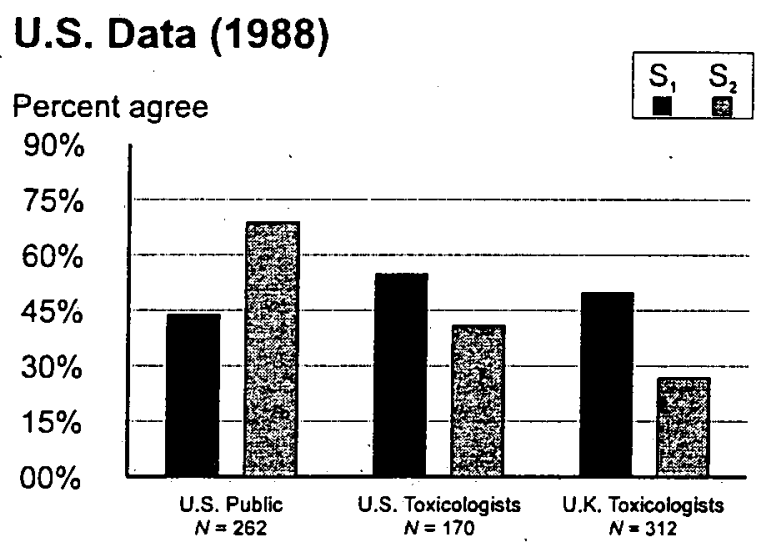

Figure 10. Agreement with two statements, $S_{1}$ and $S_{2}$, regarding the extrapolation of chemical effects in animals to chemical effects in humans.

Figure 11 presents the responses for $\mathrm{S}_{1}$ and $\mathrm{S}_{2}$ among men and women toxicologists in the UK (208 men and 92 women). Here we see another interesting finding. The men agree less on the second statement than on the first, but the women agree more, just like the general public.

Womentoxicologists are more willing than men to say that one can generalize to humans from the positive carcinogenicity findings in animals.

We created a change score between statements $S_{1}$ and $S_{2}$, with each individual getting a score of increasing agreement, decreasing agreement, or no change. Selected correlations between this change score and other items in the survey of British toxicologists are shown in Table 5. A

${ }^{1}$ This is actually a very surprising result, given the heavy reliance on animal studies in toxicology.

${ }^{2}$ This pattern suggests that animal studies may be scaring the public without informing science. 


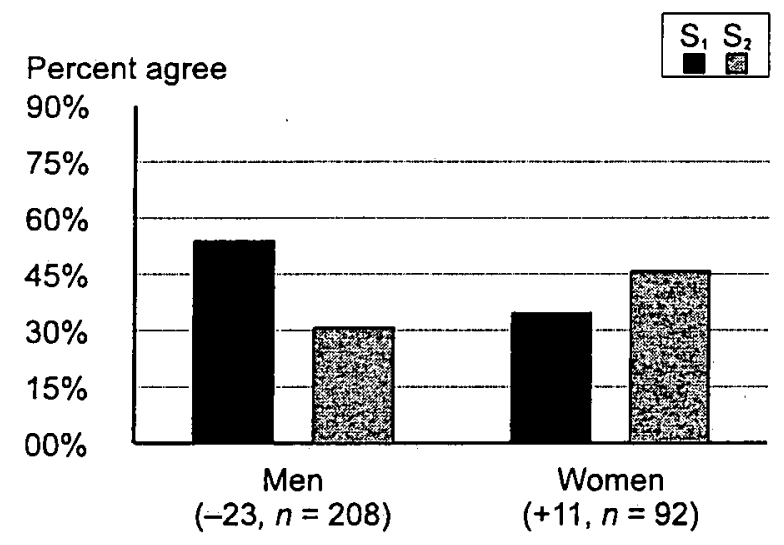

Figure 11. Agreement of men and women toxicologists in the United Kingdom with two statements regarding extrapolation of chemical effects in animals to chemical effects in humans.

positive change score (meaning greater agreement with $S_{2}$ than with $S_{1}$ ) was associated with:

- Higher mean perceptions of risk across 25 hazards (the risk-perception index)

- Rating pesticides and industrial chemicals as "bad" on the affective rating task

- Being female

- Being younger

- Agreeing that "I have little control over risks to my health"

\section{Table 5}

\section{Correlations with the $\mathrm{S}_{2}-\mathrm{S}_{1}$ Change Score}

British Society of Toxicology $(N=312)$

- Belief that there is a threshold dose for nongenotoxic carcinogens

- Risk Perception Index (average across 25 items)

- Pesticides: Bad - Good rating

- Industrial chemicals: Bad - Good rating

- Sex: female

- Age: young

- Agree to accept some risk to strengthen economy

- I have little control over health risks

- Respondent works in an academic position

- Technology is important for social well being

- Economic growth is necessary for quality of life

- Respondent works in industry

Note: All correlations are significant at $p<.01$. 
- Holding an academic position rather than a position in industry

- Disagreeing that technology is important for social well-being

- Disagreeing that economic growth is necessary for good quality of life.

These studies of intuitive toxicology have yielded a number of intriguing findings. One is the low percentage of agreement that animal studies can predict human health effects. Another is that toxicologists show even less confidence in studies that find cancer in animals resulting from chemical exposure. The public has high confidence in animal studies that find cancer.

Disagreements among toxicologists are systematically linked to gender, affiliation (academic vs. other), worldviews, and affect. Thus affective and sociopolitical factors appear to influence scientists' risk evaluations in much the same way as they influence the public's perceptions. ${ }^{3}$

\subsection{Trust}

\subsection{The Importance of Trust}

The research described above has painted a portrait of risk perception influenced by the interplay of psychological, social, and political factors. Members of the public and experts can disagree about risk because they define risk differently, have different worldviews, different affective experiences and reactions, or different social status. Another reason why the public often rejects scientists' risk assessments is lack of trust. Trust in risk management, like risk perception, has been found to correlate with gender, race, worldviews, and affect.

${ }^{3}$ Although we have focused only on the relationship between toxicologists' reaction to chemicals and their responses to $S_{1}$ and $S_{2}$, there were may other links between affect and attitudes in the survey. For example, the very simple bad-good rating of pesticides correlated significantly $(r=.20)$ with agreement that there is a threshold dose for nongenotoxic carcinogens. The same rating correlated .27 with the belief that synergistic effects of chemicals cause animal studies of single chemicals to underestimate risk to humans. 
Social relationships of all types, including risk management, rely heavily on trust. Indeed, much of the contentiousness that has been observed in the risk-management arena has been attributed to a climate of distrust that exists between the public, industry, and risk-management professionals (e.g., Slovic, 1993; Slovic, Flynn et al., 1991). The limited effectiveness of riskcommunication efforts can be attributed to the lack of trust. If you trust the risk manager, communication is relatively easy. If trust is lacking, no form or process of communication will be satisfactory (Fessenden-Raden, Fitchen, \& Heath, 1987).

\subsection{How Trust Is Created and Destroyed}

One of the most fundamental qualities of trust has been known for ages. Trust is fragile. It is typically created rather slowly, but it can be destroyed in an instant $\longrightarrow$ by a single mishap or mistake. Thus, once trust is lost, it may take a long time to rebuild it to its former state. In some instances, lost trust may never be regained. Abraham Lincoln understood this quality. In a letter to Alexander McClure, he observed: "If you once forfeit the confidence of your fellow citizens, you can never regain their respect and esteem" [italics added].

The fact that trust is easier to destroy than to create reflects certain fundamental mechanisms of human psychology called here "the asymmetry principle." When it comes to winning trust, the playing field is not level. It is tilted toward distrust, for each of the following reasons:

1. Negative (trust-destroying) events are more visible or noticeable than positive (trustbuilding) events. Negative events often take the form of specific, well-defined incidents such as accidents, lies, discoveries of errors, or other mismanagement. Positive events, while sometimes visible, more often are fuzzy or indistinct. For example, how many positive events are represented by the safe operation of a nuclear power plant for one day? Is this one event? dozens of events? 
hundreds? There is no precise answer. When events are invisible or poorly defined, they carry little or no weight in shaping our attitudes and opinions.

2. When events are well-defined and do come to our attention, negative (trust-destroying) events carry much greater weight than positive events. This important psychological tendency is illustrated by a study in which 103 college students rated the impact on trust of 45 hypothetical news events pertaining to the management of a large nuclear power plant in their community (Slovic, 1993). Some of these events were designed to be trust increasing, such as:

- There have been no reported safety problems at the plant during the past year.

- There is careful selection and training of employees at the plant.

- Plant managers live nearby the plant.

- The county medical examiner reports that the health of people living near the plant is better than the average for the region.

Other events were designed to be trust decreasing, such as:

- A potential safety problem was found to have been covered up by plant officials.

- Plant safety inspections are delayed in order to meet the electricity production quota for the month.

- A nuclear power plant in another state has a serious accident.

- The county medical examiner reports that the health of people living near the plant is worse than the average for the region.

The respondents were asked to indicate, for each event, whether their trust in the management of the plant would be increased or decreased upon learning of that event. After doing this, they rated how strongly their trust would be affected by the event on a scale ranging from 1 (very small impact on trust) to 7 (very powerful impact on trust). 
Trust, Emotion, Sex, Politics, and Science $\cdot 33$

The percentages of Category 7 ratings, shown in Figure 12, demonstrate that negative events are seen as far more likely to have a powerful effect on trust than are positive events. The data shown in Table 6 are typical. The negative event, reporting plant neighbors' health as worse than average, was rated 6 or 7 on the impact scale by $50.0 \%$ of the respondents. A matched event, reporting neighbors' health to be better than average, was rated 6 or 7 by only $18.3 \%$ of the respondents. 
Trust, Emotion, Sex, Politics, and Science $\cdot 34$

Local board authority to close plant

Evacuation plan exists

On-site government inspector

Rewarded for finding problems

Responsive to any sign of problems

Effective emergency action taken

Local advisory board established

Public encouraged to tour plant

Mandatory drug testing

No problems for five years

Hold regular public hearings

Employees carefully trained

Conduct emergency training

Community has access to records

Serious accident is controlled

Nearby health is good

Monitor radioactive emissions

Employees informed of problems

Neighbors notified of problems

No evidence of withholding information

Contribute to local charities

Employees closely supervised

Try to meet with public

Managers live nearby

Operates according to regulations

No problems in past year

Record keeping is good
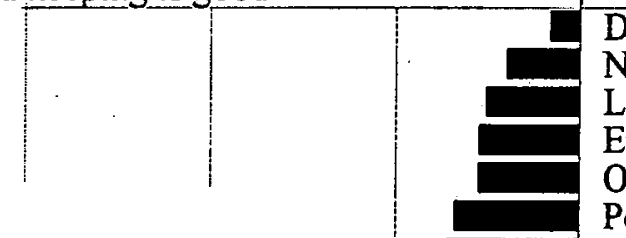

Don't contribute to local charities

No public hearings

Little communication with community

Emergency response plans not rehearsed

Officials live far away

Poor record keeping

TRUST

DECREASING

Accident occurs in another state

Accused of releasing radiation

Denied access to records

Employees not informed of problems

Delayed inspections

Public tours not permitted

Health nearby worse than average

Official lied to government

Serious accident is controlled

No adequate emergency response plan

Plant covered up problem

Employees drunk on job

Records were falsified

$-60 \%$

$-40 \% \quad-20 \%$

$0 \%$

$20 \%$

$40 \%$

$60 \%$

Percent "very powerful impact"

Figure 12. Differential impact of trust-increasing and trust-decresing events. Note: only percentages of Category 7 ratings (very powerful impact) are shown here. Source: Slovic (1993). 
There was only one event perceived to have any substantial impact on increasing trust. This event stated that:

"An advisory board of local citizens and environmentalists is established to monitor the plant and is given legal authority to shut the plant down if they believe it to be unsafe."

Table 6

Judged Impact of Trust-Increasing Event and a Similar Trust-Decreasing Event

\begin{tabular}{|c|c|c|c|c|c|c|}
\hline \multicolumn{7}{|c|}{ Impact on Trust } \\
\hline $\begin{array}{l}\text { very } \\
\text { small }\end{array}$ & & & & & & $\begin{array}{r}\text { very } \\
\text { powerful }\end{array}$ \\
\hline 1 & 2 & 3 & 4 & 5 & 6 & 7 \\
\hline
\end{tabular}

Trust-Increasing Event

The county medical examiner reports that the health of people living near the plant is better than average.

$\begin{array}{lllllll}21.5 & 14.0 & 10.8 & 18.3 & 17.2 & 16.1 & 2.2\end{array}$

\section{Trust-Decreasing Event}

The county medical examiner reports that the health of people living near the plant is worse than average.

\begin{tabular}{lllllll}
3.0 & 8.0 & 2.0 & 16.0 & 21.0 & 26.0 & 24.0 \\
\hline
\end{tabular}

Note. Cell entries indicate the percentage of respondents in each impact rating category. Source: Slovic, 1993.

This strong delegation of authority to the local public was rated 6 or 7 on the impact scale by $38.4 \%$ of the respondents. Although this was a far stronger showing than for any other positive event, it would have been a rather average performance in the distribution of impacts for negative events.

The importance of an event is at least in part related to its frequency (or rarity). An accident in a nuclear plant is more informative with regard to risk than is a day (or even a large number of 
Trust, Emotion, Sex, Politics, and Science $\cdot 36$

days) without an accident. Thus, in systems where we are concerned about low-probability/high consequence events, adverse events will increase our perceptions of risk to a much greater degree than favorable events will decrease them.

3. Adding fuel to the fire of asymmetry is yet another idiosyncrasy of human psychology sources of bad (trust-destroying) news tend to be seen as more credible than sources of good news. The findings reported in Section 4.4 illustrate this point. In general, confidence in the validity of animal studies is not particularly high. However, when told that a study has found that a chemical is carcinogenic in animals, members of the public express considerable confidence in the validity of this study for predicting health effects in humans.

4. Another important psychological tendency is that distrust, once initiated, tends to reinforce and perpetuate distrust. This occurs in two ways. First, distrust tends to inhibit the kinds of personal contacts and experiences that are necessary to overcome distrust. By avoiding others whose motives or actions we distrust, we never get to see that these people are competent, well-meaning, and trustworthy. Second, initial trust or distrust colors our interpretation of events, thus reinforcing our prior beliefs. Persons who trusted the nuclear power industry saw the events at Three Mile Island as demonstrating the soundness of the "defense in depth" principle, noting that the multiple safety systems shut the plant down and contained most of its radiation. Persons who distrusted nuclear power prior to the accident took an entirely different message from the same events, perceiving that those in charge did not understand what was wrong or how to fix it and that catastrophe was averted only by sheer luck.

\section{3 "The System Destroys Trust"}

Thus far we have been discussing the psychological tendencies that create and reinforce distrust in situations of risk. Appreciation of those psychological principles leads us toward a new 
Trust, Emotion, Sex, Politics, and Science $\cdot 37$

perspective on risk perception, trust, and conflict. Conflicts and controversies surrounding risk management are not due to public irrationality or ignorance but, instead, can be seen as expected side effects of these psychological tendencies, interacting with a highly participatory Democratic system of government and amplified by certain powerful technological and social changes in society. The technological change has given the electronic and print media the capability (effectively utilized) of informing us of news from all over the world - often right as it happens. Moreover, just as individuals give greater weight and attention to negative events, so do the news media. Much of what the media reports is bad (trust-'destroying) news (Koren \& Klein, 1991; Lichtenberg \& MacLean, 1992).

The second important change, a social phenomenon, is the rise of powerful special interest groups, well funded (by a fearful public) and sophisticated in using their own experts and the media to communicate their concerns and their distrust to the public in order to influence risk policy debates and decisions (Wall Street Journal, 1989). The social problem is compounded by the fact that we tend to manage our risks within an adversarial legal system that pits expert vs. expert, contradicting each other's risk assessments and further destroying the public trust.

The young science of risk assessment is too fragile, too indirect, to prevail in such a hostile atmosphere. Scientific analysis of risks cannot allay our fears of low-probability catastrophes or delayed cancers unless we trust the system. In the absence of trust, science (and risk assessment) can only feed public concerns, by uncovering more bad news. A single study demonstrating an association between exposure to chemicals or radiation and some adverse health effect cannot easily be offset by numerous studies. failing to find such an association. Thus, for example, the more studies that are conducted looking for effects of electric and magnetic fields or other difficult to evaluate hazards, the more likely it is that these studies will increase public concerns, even if the 
Trust, Emotion, Sex, Politics, and Science $\cdot 38$

majority of these studies fail to find any association with ill health (MacGregor, Slovic, \& Morgan, 1994; Morgan et al., 1985). In short, because evidence for lack of risk often carries little weight, risk-assessment studies tend to increase perceived risk.

\subsection{Resolving Risk Conflicts: Where Do We Go From Here?}

\subsection{Technical Solutions to Risk Conflicts}

There has been no shortage of high-level attention given to the risk conflicts described above. One prominent proposal by Justice Stephen Breyer (1993) attempts to break what he sees as a vicious circle of public perception, congressional overreaction, and conservative regulation that leads to obsessive and costly preoccupation with reducing negligible risks as well as to inconsistent standards among health and safety programs. Breyer sees public misperceptions of risk and low levels of mathematical understanding at the core of excessive regulatory response. His proposed solution is to create a small centralized administrative group charged with creating uniformity and rationality in highly technical areas of risk management. This group would be staffed by civil servants with experience in health and environmental agencies, Congress, and OMB. A parallel is drawn between this group and the prestigious Conseil d'Etat in France.

Similar frustration with the costs of meeting public demands led the 104th Congress to introduce numerous bills designed to require all major new regulations to be justified by extensive risk assessments. Proponents of this legislation argue that such measures are necessary to ensure that regulations are based upon "sound science" and effectively reduce significant risks at reasonable costs.

The language of this proposed legislation reflects the traditional narrow view of risk and risk assessment based "... only on the best reasonably available scientific data and scientific 
Trust, Emotion, Sex, Politics, and Science $\cdot 39$

understanding ..." Agencies are further directed to develop a systematic program for external peer review using "expert bodies" or "other devices comprised of participants selected on the basis of their expertise relevant to the sciences involved ..." (U.S. Senate, 1995, pp. 57-58). Public participation in this process is advocated, but no mechanisms for this are specified.

The proposals by Breyer and the 104th Congress are typical in their call for more and better technical analysis and expert oversight to rationalize risk management. There is no doubt that technical analysis is vital for making risk decisions better informed, more consistent, and more accountable. However, value conflicts and pervasive distrust in risk management cannot easily be reduced by technical analysis. Trying to address risk controversies primarily with more science is, in fact, likely to exacerbate conflict.

\subsection{Process-Oriented Solutions}

A major objective of this paper has been to demonstrate the complexity of risk and its assessment. To summarize the earlier discussions, danger is real, but risk is socially constructed. Risk assessment is inherently subjective and represents a blending of science and judgment with important psychological, social, cultural, and political factors. Finally, our social and democratic institutions, remarkable as they are in many respects, breed distrust in the risk arena.

Whoever controls the definition of risk controls the rational solution to the problem at hand. If you define risk one way, then one option will rise to the top as the most cost-effective or the safest or the best. If you define it another way, perhaps incorporating qualitative characteristics and other contextual factors, you will likely get a different ordering of your action solutions (Fischhoff, Watson, \& Hope, 1984). Defining risk is thus an exercise in power.

Scientific literacy and public education are important, but they are not central to risk controversies. The public is not irrational. The public is influenced by emotion and affect in a way 
Trust, Emotion, Sex, Politics, and Science $\cdot 40$

that is both simple and sophisticated. So are scientists. The public is influenced by worldviews, ideologies, and values; so are scientists, particularly when they are working at the limits of their expertise.

The limitations of risk science, the importance and difficulty of maintaining trust, and the subjective and contextual nature of the risk game point to the need for a new approach - one that focuses upon introducing more public participation into both risk assessment and risk decision making in order to make the decision process more democratic, improve the relevance and quality of technical analysis, and increase the legitimacy and public acceptance of the resulting decisions. Work by scholars and practitioners in Europe and North America has begun to lay the foundations for improved methods of public participation within deliberative decision processes that include negotiation, mediation, oversight committees, and other forms of public involvement (English, 1992; Kunreuther, Fitzgerald, \& Aarts, 1993; National Research Council, in press; Renn, Webler, \& Johnson, 1991; Renn, Webler, \& Wiedemanin, 1995).

Recognizing interested and affected citizens as legitimate partners in the exercise of risk assessment is no short-term panacea for the problems of risk management. But serious attention to participation and process issues may, in the long run, lead to more satisfying and successful ways to manage risk.

\subsection{References}

Alhakami, A. S., \& Slovic, P. (1994). A psychological study of the inverse relationship between perceived risk and perceived benefit. Risk Analysis, 14(6), 1085-1096.

Alpen, J. (1993). Science education: The pipeline is leaking women all the way along. Science, 260, 409-411. 
Trust, Emotion, Sex, Politics, and Science • 41

Barke, R., Jenkins-Smith, H., \& Slovic, P. (1995). Risk perceptions of men and women scientists [Report No. 95-6]. Eugene, OR: Decision Research.

Baumer, T. L. (1978). Research on fear of crime in the United States. Victimology, 3, $254-$ 264.

Breyer, S. (1993). Breaking the vicious circle: Toward effective risk regulation. Cambridge, MA: Harvard University.

Brody, C. J. (1984). Differences by sex in support for nuclear power. Social Forces, 63, 209228.

Buss, D. M., Craik, K. H., \& Dake, K. M. (1986). Contemporary worldviews and perception of the technological system. In V. T. Covello, J. Menkes \& J. Mumpower (Eds.), Risk evaluation and management (pp. 93-130). New York: Plenum.

Carney, R. E. (1971). Attitudes toward risk. In R. E. Carney (Ed.), Risk taking behavior: Concepts, methods, and applications to smoking and drug abuse. Springfield, IL: Charles C. Thomas.

Cohen, B. L. (1985). Criteria for technology acceptability. Risk Analysis, 5, 1-2.

Covello, V. T., Flamm, W. G., Rodricks, J. V., \& Tardiff, R. G. (1983). The analysis of actual versus perceived risks. New York: Plenum.

Dake, K. (1991). Orienting dispositions in the perception of risk: An analysis of contemporary worldviews and cultural biases. Journal of Cross-Cultural Psychology, 22, 61-82.

Dake, K. (1992). Myths of nature: Culture and the social construction of risk. Journal of Social Issues, 48, 21-37.

Dean, W. R., \& Thompson, P. B. (1995). The varieties of risk [Environmental Risk Management Working Paper ERC 95-3]. Edmonton: University of Alberta. 
Trust, Emotion, Sex, Politics, and Science 42

DeJoy, D. (1992). An examination of gender differences in traffic accident risk perception. Accident Analysis and Prevention.

DuPont, R. L. (1980). Nuclear phobia - Phobic thinking about nuclear power. Washington, DC: The Media Institute.

English, M. R. (1992). Siting low-level radioactive waste disposal facilities. New York: Quorum.

Fessenden-Raden, J., Fitchen, J. M., \& Heath, J. S. (1987). Providing risk information in communities: Factors influencing what is heard and accepted. Science Technology and Human Values, 12, 94-101.

Fischhoff, B., Slovic, P., Lichtenstein, S., Read, S., \& Combs, B. (1978). How safe is safe enough? A psychometric study of attitudes towards technological risks and benefits. Policy Sciences, 9, 127-152.

Fischhoff, B., Watson, S., \& Hope, C. (1984). Defining risk. Policy Sciences, 17, 123-139.

Flynn, J., Slovic, P., \& Mertz, C. K. (1994). Gender, race, and perception of environmental health risks. Risk Analysis, 14(6), 1101-1108.

Funtowicz, S. O., \& Ravetz, J. R. (1992). Three types of risk assessment and the emergence of post-normal science. In S. Krimsky \& D. Golding (Eds.), Social theories of risk (pp. 251-274). Westport, CT: Praeger.

Gilligan, C. (1982). In a difference voice: Psychological theory and women's development. Cambridge, MA: Harvard.

Gregory, R., Flynn, J., \& Slovic, P. (1995). Technological stigma. American Scientist, 83, $220-223$. 
Trust, Emotion, Sex, Politics, and Science $\bullet 43$

Gregory, R., Lichtenstein, S., \& MacGregor, D. G. (1993). The role of past states in determining reference points for policy decisions. Organizational Behavior and Human Decision Processes, 55, 195-206.

Gutelling, J. M., \& Wiegman, O. (1993). Gender-specific reactions to environmental hazards in the Netherlands. Sex Roles, 28, 433-447.

Gwarțney-Gibbs, P. A., \& Lach, D. H. (1991): Sex differences in attitudes toward nuclear war. Journal of Peace Research, 28, 161-174.

Jasper, J. M. (1990). Nuclear politics: Energy and the state in the United States, Sweden, and France. Princețon, NJ: Princeton University Press.

Jenkins-Smith, H. C. (1993). Nuclear imagery and regional stigma: Testing hypotheses of image acquisition and valuation regarding Nevada [Technical report]. Albuquerque: University of New Mexico, Institute for Public Policy.

Johnson, E. J., \& Tversky, A. (1983). Affect, generalization, and the perception of risk. Journal of Personality and Social Psychology, 45, 20-31.

Koren, G., \& Klein, N. (1991). Bias against negative studies in newspaper reports of medical research. Journal of the American Medical Association, 266, 1824-1826.

Kraus, N., Malmfors, T., \& Slovic, P. (1992). Intuitive toxicology: Expert and lay judgments of chemical risks. Risk Analysis, 12, 215-232.

Krimsky, S., \& Golding, D. (1992). Social theories of risk. Westport, CT: PraegerGreenwood.

Kunreuther, H. (In press). Mitigating disaster losses through insurance. Journal of Risk and Uncertainty. 
Trust, Emotion, Sex, Politics, and Science $\cdot 44$

Kunreuther, H., Fitzgerald, K., \& Aarts, T. D. (1993). Siting noxious facilities: A test of the facility siting credo. Rịsk Analysis, 13, 301-318.

Lichtenberg, J., \& MacLean, D. (1992). Is good news no news? The Geneva papers on risk and insurance, $17,362-365$.

MacGregor, D., Slovic, P., \& Morgan, M. G. (1994). Perception of risks from electromagnetic fields: A psychometric evaluation of a risk-communication approach. Risk Analysis, $14(5), 815-828$.

Malmfors, T., Mertz, C. K., Neil, N., Purchase, I., \& Slovic, P. (1996). Evaluating chemical risks: Results of a survey of the British Toxicological Society [Report No. 96-1]. Eugene, OR: Decision Research.

McNeil, B. J., Pauker, S. G., Sox, H. C., Jr., \& Tversky, A. (1982). On the elicitation of preferences for alternative therapies. New England Journal of Medicine, 306, 1259-1262.

Merchant, C. (1980). The death of nature: Women, ecology, and the scientific revolution. New York: Harper \& Row.

Morgan, M. G., Slovic, P., Nair, I., Geisler, D., MacGregor, D., Fischhoff, B., Lincoln, D., \& Florig, K. (1985). Powerline frequency electric and magnetic fields: A pilot study of risk perception. Rïsk Analysis, 5, 139-149.

National Research Council. (1989). Improving risk communication. Washington, DC: National Academy Press.

National Research Council. (In press). Understanding risk: Informing decisions ịn a democratic society. Washington, DC: National Academy Press.

Otway, H. (1992). Public wisdom, expert fallibility: Toward a contextual theory of risk. In S. Krimsky \& D. Golding (Eds.), Social theories of risk (pp. 215-228). Westport, CN: Praeger. 
Trust, Emotion, Sex, Politics, and Science 45

Palm, R. I. (1995). Natural hazards: An integrative framework for research and planning. Baltimore: Johns Hopkins.

Peters, E., \& Slovic, P. (In press). The role of affect and worldviews as orienting dispositions in the perception and acceptance of nuclear power. Journal of Applied Social Psychology.

Pidgeon, N., Hood, C., Jones, D., Turner, B., \& Gibson, R. (1992). Risk perception. In Royal Society Study Group (Ed.), Risk: Analysis, perception and management (pp. 89-134). London: The Royal Society.

Pillisuk, M., \& Acredolo, C. (1988). Fear of technological hazards: One concern or many? Social Behavior, 3, 17-24.

Renn, O., Webler, T., \& Johnson, B. (1991). Citizen participation for hazard management. Risk - Issues in Health and Safety, 3, 12-22.

Renn, O., Webler, T., \& Wiedemann, P. (1995). Fairness and competence in citizen participation. Dordrecht, The Netherlands: Klüwer.

Riger, S., Gordon, M. T., \& LeBailly, M. R. (1978). Women's fear of crime: From blaming to restricting the victim. Victimology, 3, 274-284.

Shrader-Frechette, K. S. (1991). Risk and rationality. Berkeley: University of California. Sjöberg, L., \& Drottz-Sjöberg, B. M. (1993, August). Attitudes toward nuclear waste [Rhizikon Research Report No. 12]. Stockholm, Sweden: Stockholm School of Economics, Center for Risk Research.

Slovic, P. (1987). Perception of risk. Science, 236, 280-285.

Slovic, P. (1992). Perception of risk: Reflections on the psychometric paradigm. In S. Krimsky \& D. Golding (Eds.), Social theories of risk (pp. 117-152). New York: Praeger. 
Trust, Emotion, Sex, Politics, and Science $\bullet 46$

Slovic, P. (1993). Perceived risk, trust, and democracy: A systems perspective. Risk Analysis, 13, 675-682.

Slovic, P., Flynn, J., \& Layman, M. (1991). Perceived risk, trust, and the politics of nuclear waste. Science, 254, 1603-1607.

Slovic, P., Flynn, J., Mertz, C. K., \& Mullican, L. (19.93). Health risk perception in Canada [Report No. 93-EHD-170]. Ottawa: Department of National Health and Welfare.

Slovic, P., Kraus, N. N., Lappe, H., Letzel, H., \& Malmfors, T. (1989). Risk perception of prescription drugs: Report on a survey in Sweden. Pharmaceutical Medicine, 4, 43-65.

Slovic, P., Kraus, N., Lappe, H., \& Major, M. (1991). Risk perception of prescription drugs: Report on a survey in Canada. Canadian Journal of Public Health, 82, S15-S20.

Slovic, P., Layman, M., Kraus, N., Flynn, J., Chalmers, J., \& Gesell, G. (1991). Perceived risk, stigma, and potential economic impacts of a high-level nuclear waste repository in Nevada. Risk Analysis, 11, 683-696.

Spigner, C., Hawkins, W., \& Loren, W. (1993). Gender differences in perceptions of risk associated with alcohol and drug use among college students. Women and Health, 20, 87-97.

Steger, M. A., \& Witte, S. L. (1989). Gender differences in environmental orientations: A comparison of publics and activists in Canada and the U.S. West. Polit. Q., 42, 627-649.

Stern, P. C., Dietz, T., \& Kalof, L. (1993). Value orientations, gender, and environmental concerns. Environment and Behavior, 25, 322-348.

Tengs, T. D., Adams, M. E., Pliskin, J. S., Safran, D. G., Siegel, J. E., Weinstein, M. C., \& Graham, J. D. (1995). Five-hundred life-saving interventions and their cost effectiveness. Risk Analysis, 15, 369-390. 
Trust, Emotion, Sex, Politics, and Science $\cdot 47$

Tversky, A., \& Kahneman, D. (1981). The framing of decisions and the psychology of choice. Science, $211,453-458$.

U.S. Senate. (1995). The comprehensive regulatory reform act of 1995 [Dole/Johnson discussion draft to S. 343].

United States Environmental Protection Agency (U.S. EPA). (1987). Unfinished business: A comparative assessment of environmental problems. Washington, DC: Author.

Wall Street Journal. (1989, October 3). How a PR firm executed the Alar scare (pp. A1-A3).

Webster, N. (1983). Webster's new twentieth century dictionary (2nd). New York: Simon \& Schuster.

Weiner, R. F. (1993). Comment on Sheila Jasanoff's guest editorial. Risk Analysis, 13, 495496.

Wilson, R., \& Crouch, E. (1982). Risk/Benefit analysis. Cambridge, MA: Ballinger.

Wynne, B. (1992). Risk and social learning: Reification to engagement. In S. Krimsky \& D. Golding (Eds.), Social theories of risk (pp. 275-300). Westport, CT: Praeger.

Zajonc, R. B. (1980). Feeling and thinking: Preferences need no inferences. American Psychologist, 35, 151-175. 